\title{
Primary liposarcoma of the omentum
}

\author{
Y. Okajima, M. Nishikawa, M. Ohi, Y. Fukumoto, K. Kuroda and \\ H. Shimomukai ${ }^{1}$
}

\section{Departments of Internal Medicine and ${ }^{1}$ Surgery, Ikeda Municipal Hospital, 3-5-1, Johnan, Ikeda, Osaka 563, Japan}

\begin{abstract}
Summary: This report is of a 54 year old female with omental liposarcoma. Diagnosis was made by ultrasonography, computed tomography, angiography and operation. The patient was treated by surgical excision. The histological examination revealed that the tumour was round cell liposarcoma. This is the first report to our knowledge of round cell liposarcoma of the omentum.
\end{abstract}

\section{Introduction}

Although liposarcomas are fairly common soft tissue tumours of the limbs and the retroperitoneum, ${ }^{1,2}$ primary liposarcoma of the omentum is rare. ${ }^{3}$ In a literature search we could find only seven cases. Histologically four were myxoid and three were pleomorphic in type. ${ }^{4-9}$ This paper reports the first case to our knowledge of round cell liposarcoma of the omentum.

\section{Case report}

A 54 year old female was admitted in December 1990 because of leg oedema and abdominal swelling. She had been in good health until one month before admission when she noted leg oedema.

Physical examination on admission revealed a large mass in the epigastrium and bilateral leg oedema. Ultrasonography showed a large, wellencapsulated extrahepatic mass close to the liver reaching $22 \mathrm{~cm}$ below the costal margin with a smooth surface and inhomogeneous echo levels.

Laboratory investigations showed slight anaemia and elevated levels of lactic dehydrogenase $642 \mathrm{IU} / \mathrm{l}$ (normal range 242-466), neurone specific enolase $31 \mathrm{ng} / \mathrm{ml}$ (normal 0-10) and CA125 150 $\mathrm{IU} / \mathrm{ml}$ (normal range 0-35). Barium studies revealed a large mass pushing against the stomach and displacing the transverse colon. Computed tomography (CT) showed a large non-homogeneous mass of muscle density in the epigastric-pelvic region (Figure 1). Coeliac angiography showed a hypervascular tumour nourished by the two gastro-epiploic arteries.

Based on the above findings the diagnosis of omental tumour was made. At surgery the mass was solid and adhered to the antrum of the

Correspondence: Yuu Okajima, M.D.

Accepted: 14 August 1992 stomach. The cut surface of the resected tumour was hypervascular and yellowish grey in colour. It measured $27 \times 17 \times 11 \mathrm{~cm}$ in diameter and weighed $2,300 \mathrm{~g}$. No metastasis was observed.

Microscopic examination disclosed that the tumour consisted of round cells with small to moderate sized round nuclei. Many of the tumour cells contained small to moderate sized fatty globules in their cytoplasms. The final histological diagnosis was made of round cell type of liposarcoma (Figure 2).

\section{Discussion}

Liposarcoma is one of the more common types of malignant tumours usually arising in soft tissues. ${ }^{1,2,10}$ Common sites are in the deeper soft tissues, especially in the gluteal region, thighs, popliteal fossa, shins and the retroperitoneum. ${ }^{2} \mathrm{On}$ the other hand, liposarcoma of the omentum is rare, ${ }^{3}$ only seven cases of liposarcoma of the

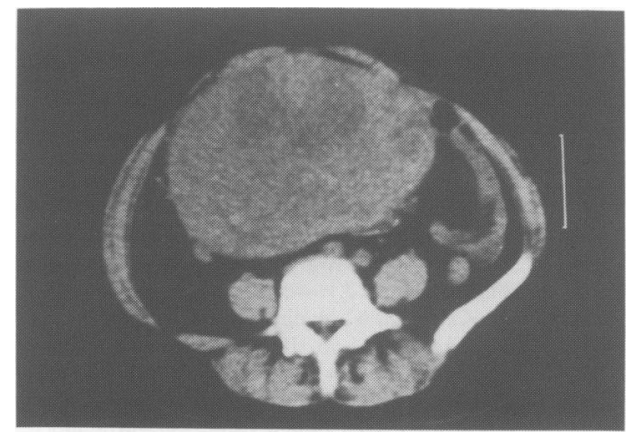

Figure 1 Computed tomography showing a large nonhomogeneous mass in the epigastoric-pelvic region. The liver is normal and no lymph node metastasis is observed. 


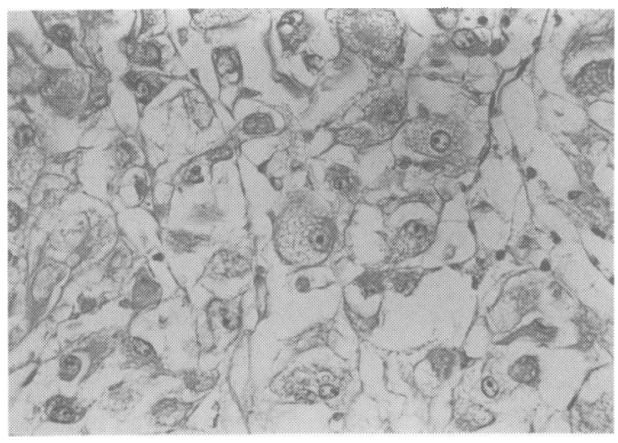

Figure 2 Microscopic examination showing the tumour consisting of a mass of round cells, with small to moderate sized round nuclei. Many of the tumour cells contain small to moderate sized fatty globules in their cytoplasms $(H \& E \times 200)$.

omentum having been reported..$^{4-9}$ Liposarcoma is divided into four groups according to histological pattern: myxoid cell, round cell, well-differentiated, and pleomorphic types. ${ }^{11}$ Histological types of the seven reported cases of liposarcoma of the omentum were pleomorphic and myxoid types. ${ }^{4-9}$ Round cell liposarcoma of the omentum has not been reported until the present case.

Signs and symptoms of omental tumours were described as painless, progressive abdominal distention in three of the cases, and abdominal pain and discomfort in the others. ${ }^{4-9}$ In this case, leg

\section{References}

1. Rosai, J. (ed.) Ackerman's Surgical Pathology. C.V. Mosby Company, London, 1989, pp. 1575-1579.

2. Lattes, R. Liposarcoma - tumors of the soft tissues. AFIP 1981, 1: $146-159$

3. Stout, A.P., Hendry, J. \& Purdie, F.J. Primary solid tumours of the great omentum. Cancer 1963, 16: 231-243.

4. Menne, F.R. \& Birge, R.F. Primary liposarcoma of the great omentum. Arch Pathol 1936, 22: 823-828.

5. Robb, W.A.T. Liposarcoma of the greater omentum. $\mathrm{Br} J$ Surg 1960, 47: 537-539.

6. McAvoy, J.M., Fee, H.J., Roth, J.A. \& Dainko, E.A. Primary liposarcoma of the omentum. Arch Surg 1978, 113: 870-872.

7. Kadow, C. \& Amery, A.H. Primary liposarcoma of the omentum: a rare intra-abdominal tumour. Br J Clin Pract 1989, 43: 460-462.

8. Ihara, S., Soga, T., Kato, J., Yosiga, H. \& Yamazaki, Y. Primary omental lipasarcoma. Chu-sei-byoin-si 1988, 9: 111 112.

9. Aida, Y., Obi, Y., Masuzawa, S. et al. A case of liposarcoma arising from omentum. Kyo-sai-i-ho 1990, 39: 550-555.

10. Takagi, H., Kato, K., Yamada, E. et al. Six recent liposarcomas including largest to date. J Surg Oncol 1984, 26: 260-267.

11. Enzinger, F.M. \& Winslow, D.J. Liposarcoma - a study of 103 cases. Virchows Arch Pathol 1962, 335: 367-388.

12. Yui-Chiu, V. \& Chiu, L. Ultrasonography and computed tomography of retroperitoneal liposarcoma. J Computed Tomogr 1981, 5: 98-109. oedema produced by the compression on the inferior vena cava by the tumour was the only symptom.

In the diagnosis of omental tumour, contrast radiography may show displacement or compression on adjacent organs, and ultrasonography or CT scanning may differentiate them from cystic lesions. Angiography may also suggest the origin of the mass.

In this case, hypervascular arteries from the epiplogastric arteries suggested that the tumour was sarcoma from the omentum. Yiu-Chiu and Chiu demonstrated that the CT pattern of liposarcoma is a fatty, low attenuation mass with enhancing intervening thick, irregular, fibrous strands traversing it. ${ }^{12}$ In this case, CT intensity of the tumour was similar to muscle. It was not clear that the tumour contained fat. However, Hunter et al. report that denser lesions tend to occur in the malignant types, whereas less aggressive tumours have a higher fat content and lower density. ${ }^{13}$ In the other reported cases the diagnosis was made only after surgery.

Radical excision of the tumour offers the possibility of longer survival and a disease-free interval. ${ }^{14-16}$ In some cases, adjuvant chemo- and/or radiotherapy has been carried out. As the value of additional chemotherapy has not been establishedo and high dose-radiotherapy to the abdomen mas produce severe complications, no chemo- and/o radiotherapy was given in this case. ${ }^{10,14-19}$ The patient remains well now 10 months after surgery.

13. Hunter, J.G., Johnson, W.H. \& Genant, H.K. Computed tomography evaluation of fatty tumors of somatic soft tissue. Clinical utility and radiologic-pathologic correlation. Skeletal Radiol 1979, 4: 79-91.

14. Kinne, D.W., Chu, F.C.H., Huvos, A.G., Yagoda, A. \& Fortner, J.G. Treatment of primary and recurrent retroperitoneal liposarcoma. Twenty-five-year experience at Memorial Hospital. Cancer 1973, 31: 53-56.

15. Elliott, T.E., Albertazzi, V.J. \& Danto, L.A. Pancreatic liposarcoma. Case report with review of retro-peritoneal liposarcomas. Cancer 1980, 45: 1720-1723.

16. Glenn, J., Sindelar, W.F., Kinsella, T. et al. Results of multimodality therapy of resectable soft-tissue sarcomas of the retroperitoneum. Surgery 1985, 93: 316-325.

17. Gupta, T.K., Patel, M.K., Chaudhuri, P.K. \& Briele, H.A. The role of chemotherapy as an adjuvant to surgery in the initial treatment of primary soft tissue sarcomas in adults. $J$ Surg Oncol 1982, 19: 139-144.

18. Moore, S.V. \& Aldrete, J.S. Primary retroperitoneal sarcomas. The role of surgical treatment. Am J Surg 1981, 142: 358-361.

19. Roswit, B., Malsky, S.J. \& Reid, C.B. Severe radiation injuries of the stomach, small intestine, colon and rectum. $A m$ $J$ Roentgen 1972, 114: 460-475. 